\title{
Smoking of crack cocaine as a risk factor for HIV infection among people who use injection drugs
}

\author{
Kora DeBeck MPP, Thomas Kerr PhD, Kathy Li PhD, Benedikt Fischer PhD, Jane Buxton MD, \\ Julio Montaner MD, Evan Wood MD PhD
}

Previously published at www.cmaj.ca

$\infty \quad$ See related commentary by Celentano and Sherman, page 571

\section{ABSTRACT}

Background: Little is known about the possible role that smoking crack cocaine has on the incidence of HIV infection. Given the increasing use of crack cocaine, we sought to examine whether use of this illicit drug has become a risk factor for HIV infection.

Methods: We included data from people participating in the Vancouver Injection Drug Users Study who reported injecting illicit drugs at least once in the month before enrolment, lived in the greater Vancouver area, were HIVnegative at enrolment and completed at least 1 follow-up study visit. To determine whether the risk of HIV seroconversion among daily smokers of crack cocaine changed over time, we used Cox proportional hazards regression and divided the study into 3 periods: May 1, 1996-Nov. 30, 1999 (period 1), Dec. 1, 1999-Nov. 30, 2002 (period 2), and Dec. 1, 2002-Dec. 30, 2005 (period 3).

Results: Overall, 1048 eligible injection drug users were included in our study. Of these, 137 acquired HIV infection during follow-up. The mean proportion of participants who reported daily smoking of crack cocaine increased from $11.6 \%$ in period 1 to $39.7 \%$ in period 3 . After adjusting for potential confounders, we found that the risk of HIV seroconversion among participants who were daily smokers of crack cocaine increased over time (period 1: hazard ratio [HR] 1.03, 95\% confidence interval $[\mathrm{Cl}]$ 0.57-1.85; period 2: HR 1.68, 95\% Cl 1.01-2.80; and period 3: HR 2.74, 95\% Cl 1.06-7.11).

Interpretation: Smoking of crack cocaine was found to be an independent risk factor for HIV seroconversion among people who were injection drug users. This finding points to the urgent need for evidence-based public health initiatives targeted at people who smoke crack cocaine.

$\mathrm{P}$ eople who inject illegal drugs are known to be at heightened risk of HIV infection and other bloodborne diseases. In 2007, more than $20 \%$ of all new cases of HIV infection recorded in Canada were attributed to injection drug use. ${ }^{1}$ Behaviours associated with the use of particular injection drugs (e.g., cocaine and heroin) have been identified as key factors driving HIV transmission among drug users in various settings. ${ }^{2}$ However, over the last decade, significant changes in the popularity of specific illegal drugs have been observed. ${ }^{3.4}$ In recent years, cities across Canada have experienced an explosive increase in the use of crack cocaine, whereas some drugs, including heroin, appear to be less commonly used..$^{5-7}$ The proportion of drug users who smoke crack cocaine and are homeless or have marginal housing has recently been reported to be as high as $86.6 \%$ in Vancouver, $66.7 \%$ in Edmonton and $62.4 \%$ in Toronto. ${ }^{8}$

In the United States, a seminal cross-sectional study involving inner-city young adults showed that smoking of crack cocaine was associated with HIV infection. ${ }^{9}$ However, in Canada, despite the documentation of changing patterns of drug use in many communities, ${ }^{8}$ little is known about the impact that increased smoking of crack cocaine has had on the HIV epidemic. This is problematic because public health programs for people who smoke crack cocaine have been highly controversial in Canada. ${ }^{6}$ We conducted a longitudinal study to evaluate whether smoking of crack cocaine has emerged as a risk factor for HIV infection among people who inject drugs.

\section{Methods}

\section{Study design}

We obtained data from the Vancouver Injection Drug Users Study, an open prospective cohort study that has been ongoing since May 1996. Details of that study's methods have been described previously. ${ }^{10}$ In brief, eligibility is limited to people who, at recruitment, report injecting illicit drugs at

From the British Columbia Centre for Excellence in HIVIAIDS (DeBeck, Kerr, Li, Montaner, Wood); the Division of AIDS, Department of Medicine (Kerr, Montaner, Wood), University of British Columbia; the Centre for Applied Research in Mental Health and Addictions (CARMHA), Faculty of Health Sciences (Fischer), Simon Fraser University; the School of Population and Public Health (Buxton), University of British Columbia, Vancouver, BC

Cite as CMAJ 2009. DOI:10.1503/cmaj.082054 
least once in the previous month, live in the greater Vancouver area and provide written informed consent. Extensive outreach is undertaken in an effort to obtain a representative sample of people in the city who use injection drugs. ${ }^{2}$ At baseline and semi-annually, participants are asked to complete an interviewer-administered questionnaire and provide a blood sample for serologic testing. The questionnaire is designed to elicit demographic data and information about patterns of recent drug use, risk behaviours for HIV infection, health status, and contact with health care and addiction treatment services. At each study visit, participants are reimbursed $\$ 20$ for their time. The study has received ethics approval from the Providence Health Care/University of British Columbia's Research Ethics Board.

For our analyses, we used data for participants who were HIV-negative at enrolment and who completed at least 1 follow-up study visit. Because prior studies have reported the rising use of crack cocaine in Canada, the primary focus of our study was on crack cocaine. This drug is almost always smoked rather than injected or snorted. ${ }^{11}$ Therefore, we restricted all measures of use of crack cocaine to smoking. We did not include reports of injecting crack, which were captured through questions about cocaine injection.

\section{Variables of interest}

The primary outcome measure was time to HIV seroconversion. Because the median length of time between follow-up visits was about 6 months, as in previous analyses, ${ }^{10,12}$ we estimated the date of HIV seroconversion using the midpoint between the last negative and the first positive antibody test result. ${ }^{13}$ We selected explanatory variables of interest based on all earlier analyses of risk factors for HIV seroconversion in our setting ${ }^{14,15}$ and internationally defined traditional risk

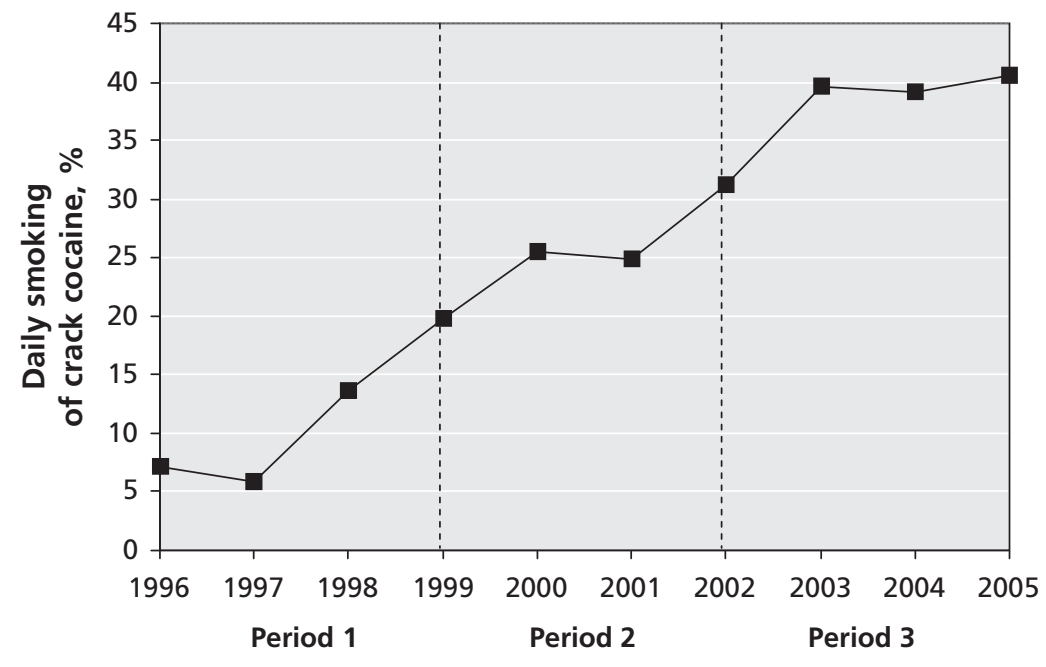

Figure 1: Proportion of 1048 participants in the Vancouver Injection Drug Users Study who reported daily smoking of crack cocaine, by calendar year of followup. Odds ratio for daily use (derived from generalized estimating equations) 1.23 (95\% confidence interval 1.21-1.26) per year. Period $1=$ May 1, 1996, to Nov. 30, 1999; period 2 = Dec. 1, 1999, to Nov. 30, 2002; period $3=$ Dec. 1, 2002, to Dec. 31, 2005. factors for HIV infection among injection drug users (e.g., borrowing of syringes, and unsafe vaginal or anal sex).${ }^{16}$ Socio-demographic variables included age (per year older), sex (female v. male), Aboriginal ethnicity (yes v. no), and number of years since first injection at time of recruitment. Data on drug use and risk behaviours in the 6 months before each follow-up visit were updated after each semi-annual visit. These variables included daily smoking of crack cocaine (yes v. no), daily injection of cocaine (yes v. no), daily injection of heroin (yes v. no), engagement in sex work (yes v. no), engagement in any unprotected sex (yes v. no) and borrowing of syringes (yes v. no). All definitions of variables were identical to those used in earlier reports. ${ }^{2}$

\section{Statistical analysis}

To examine the change in patterns of crack cocaine use over time, we examined the annual proportion of participants who reported smoking crack cocaine daily over the study period. We used generalized estimating equations for logistic regression analysis to assess for statistically significant changes. The crude rate of daily smoking of crack cocaine was presented visually as the proportion of participants who reported this behaviour at least once during each calendar year.

To test our primary hypothesis, we determined whether the hazard ratio for HIV seroconversion associated with daily smoking of crack cocaine changed over the study period. To do this, we used extended Cox proportional hazards regression analysis ${ }^{17}$ with time-varying covariables. We also divided the study period into 3 periods to examine interactions between time and all variables of interest. We defined the 3 periods by initially visually inspecting the rate of daily smoking of crack cocaine in the cohort during follow-up (Figure 1) and then dividing the 9.3-year follow-up period into 3 approximately equal periods. Period 1 included the first 3.5 years of follow-up (May 1, 1996, to Nov. 30, 1999), period 2 the next 3 years (Dec. 1, 1999, to Nov. 30, 2002) and period 3 the remaining 3 years (Dec. 1, 2002, to Dec. 31, 2005).

As a first step, we calculated the unadjusted hazard ratio for daily smoking of crack cocaine and all variables of interest. We explored any interactions with the defined study periods. In the final Cox regression model, we included all previously defined variables of interest to adjust for potential confounding. All $p$ values were 2 -sided.

\section{Results}

A total of 1603 people were recruited into the Vancouver Injection Drug Users Study between May 1, 1996, and Dec. 31, 2005. Of the 1280 (79.9\%) who were HIV negative at enrolment, we excluded $232(18.1 \%)$ because they did not return for any of the follow-up visits. These 232 participants were less likely to be Aboriginal and more likely to be younger than those included in 
our study ( $p<0.05$ ); otherwise, the 2 groups were similar in terms of sex distribution, daily cocaine injection and daily smoking of crack cocaine $(p>0.05)$. Of the 1048 participants included in our study, $373(35.6 \%)$ were female, and 273 $(26.0 \%)$ identified themselves as Aboriginal; the median age at baseline was 34 years (interquartile range 25-41). The baseline characteristics of the study participants stratified by sex are presented in Table 1. This sample contributed 9601 observations during the entire follow-up period. The median number of follow-up visits was 11 (interquartile range 5-17).

\section{Daily smoking of crack cocaine}

We observed a large increase in the proportion of participants who reported daily smoking of crack cocaine (Figure 1), from $11.6 \%$ in the first 3.5 years of follow-up (period 1), to $27.2 \%$ in the next 3 years (period 2) and to $39.7 \%$ in the last 3 years (period 3 ). The odds ratio for daily smoking of crack cocaine was 1.23 (95\% confidence interval [CI] 1.21-1.26) per year.

\section{HIV infection and daily smoking of crack cocaine}

Of the 1048 participants, 137 (13.1\%) became HIV positive during follow-up. The median length of time between the last negative and the first positive HIV antibody test result was 6.2 (interquartile range 5.7-8.3) months. The overall incidence of HIV infection was 2.7 (95\% CI 2.2-3.1) per 100 person-years. We observed a significant interaction effect between the 3 specified periods and smoking of crack cocaine $(p<0.05)$. There were no significant interaction effects with any of the other variables of interest $(p>0.05)$. Subsequently,

Table 1: Baseline characteristics of 1048 people who reported using injection drugs and were HIV negative at enrolment, stratified by sex

\begin{tabular}{|c|c|c|c|}
\hline \multirow[b]{2}{*}{ Characteristic } & \multicolumn{2}{|c|}{$\begin{array}{c}\text { Sex; no. (\%) } \\
\text { of participants* }\end{array}$} & \multirow[b]{2}{*}{ OR $(95 \% \mathrm{Cl})$} \\
\hline & $\begin{array}{l}\text { Female } \\
n=373\end{array}$ & $\begin{array}{c}\text { Male } \\
n=675\end{array}$ & \\
\hline Age, median (IQR) & $30(23-37)$ & $36(27-42)$ & $0.95(0.94-0.96)$ \\
\hline $\begin{array}{l}\text { Duration of } \\
\text { injection drug use, } \\
\text { yr, median (IQR) }\end{array}$ & $8(2-18)$ & $11(3-23)$ & $0.97(0.96-0.98)$ \\
\hline $\begin{array}{l}\text { Aboriginal } \\
\text { ethnicity }\end{array}$ & $153(41.0)$ & $120(17.8)$ & $3.22(2.42-4.28)$ \\
\hline $\begin{array}{l}\text { Daily injection } \\
\text { of cocainet }\end{array}$ & $133(35.7)$ & 202 (29.9) & $1.30(0.99-1.70)$ \\
\hline $\begin{array}{l}\text { Daily injection } \\
\text { of heroint }\end{array}$ & $173(46.4)$ & $224(33.2)$ & $1.74(1.34-2.26)$ \\
\hline $\begin{array}{l}\text { Daily smoking } \\
\text { of crack cocainet }\end{array}$ & $36 \quad(9.7)$ & $38 \quad(5.6)$ & $1.79(1.11-2.88)$ \\
\hline $\begin{array}{l}\text { Engaged in sex } \\
\text { workt }\end{array}$ & $218(58.4)$ & $65 \quad(9.6)$ & $13.20(9.50-18.33)$ \\
\hline $\begin{array}{l}\text { Engaged in } \\
\text { unprotected sext }\end{array}$ & $217(58.2)$ & $304(45.0)$ & $1.70(1.31-2.19)$ \\
\hline Borrowed syringest & $128(34.3)$ & $253(37.5)$ & $0.87(0.67-1.14)$ \\
\hline
\end{tabular}

Note: $\mathrm{Cl}=$ confidence interval, $\mathrm{IQR}=$ interquartile range.

*Unless stated otherwise.

tActivity or situation in the 6 months before enrolment. we focused on the interaction between smoking of crack cocaine and each of the 3 time periods.

Table 2 includes the unadjusted and adjusted hazard ratios (HRs) for HIV seroconversion associated with smoking of crack cocaine in each period as well as the other variables of interest. We found no association between daily smoking of crack cocaine and HIV seroconversion in the first 3.5 years of follow-up (period 1: HR 1.28, 95\% CI 0.75-2.19. There was an association in the subsequent 3 years of follow-up (period 2: HR 2.27, 95\% CI 1.44-3.61), and an even stronger association in the final 3 years of follow-up (period 3: HR 4.01, 95\% CI 1.79-8.96) (Figure 2). The findings were similar after adjustment for known HIV risk factors (Table 2).

\section{Interpretation}

In this prospective study involving participants in the Vancouver Injection Drug Users Study who were HIV negative at enrolment, we found that smoking of crack cocaine became increasingly prevalent over time. We also observed that such use of crack cocaine became an independent risk factor for HIV seroconversion over time after adjusting for potential confounders.

This finding suggests that there may be unmeasured risk factors related to the smoking of crack cocaine, or unmea-

Table 2: Factors associated with HIV seroconversion among people who reported using injection drugs

\begin{tabular}{|c|c|c|}
\hline \multirow[b]{2}{*}{ Factor } & \multicolumn{2}{|c|}{ Hazard ratio $(95 \% \mathrm{Cl})$} \\
\hline & Unadjusted & Adjusted* \\
\hline \multicolumn{3}{|l|}{$\begin{array}{l}\text { Daily smoking of } \\
\text { crack cocainet‡ }\end{array}$} \\
\hline Period 1 & $1.28(0.75-2.19)$ & $1.03(0.57-1.85)$ \\
\hline Period 2 & $2.27(1.44-3.61)$ & $1.68(1.01-2.80)$ \\
\hline Period 3 & $4.01(1.79-8.96)$ & $2.74(1.06-7.11)$ \\
\hline $\begin{array}{l}\text { Age (per year } \\
\text { increase) }\end{array}$ & $0.99(0.97-1.01)$ & $0.99(0.96-1.02)$ \\
\hline $\begin{array}{l}\text { Duration of injection } \\
\text { drug use (per year) }\end{array}$ & $0.99(0.97-1.01)$ & $0.99(0.97-1.02)$ \\
\hline Sex (female v. male) & $1.37(0.95-1.96)$ & $1.02(0.66-1.60)$ \\
\hline $\begin{array}{l}\text { Aboriginal ethnicity } \\
\text { (yes v. no) }\end{array}$ & $1.87(1.29-2.71)$ & $1.79(1.21-2.66)$ \\
\hline $\begin{array}{l}\text { Daily cocaine } \\
\text { injection } ¥ \text { (yes v. no) }\end{array}$ & $3.71(2.62-5.26)$ & $2.94(2.00-4.33)$ \\
\hline $\begin{array}{l}\text { Daily heroin } \\
\text { injection } ¥ \text { (yes v. no) }\end{array}$ & $1.55(1.10-2.20)$ & $1.05(0.71-1.54)$ \\
\hline Sex work $\ddagger$ (yes v. no) & $1.59(1.06-2.37)$ & $0.87(0.52-1.48)$ \\
\hline $\begin{array}{l}\text { Unprotected sex } \neq \\
\text { (yes v. no) }\end{array}$ & $0.89(0.62-1.30)$ & $0.82(0.55-1.22)$ \\
\hline $\begin{array}{l}\text { Syringe borrowing } \\
\text { (yes v. no) }\end{array}$ & $2.20(1.51-3.21)$ & $1.72(1.14-2.59)$ \\
\hline
\end{tabular}

Note: $\mathrm{Cl}=$ confidence interval.

*Adjusted for the variables listed in this table.

tAll estimations for daily smoking of crack cocaine include the interaction effect of the 3 study periods (period 1 = May 1, 1996, to Nov., 30 1999; period 2 = Dec. 1 1999, to Nov. 30, 2002; period 3 = Dec. 1, 2002, to Dec. 31, 2005.

¥Activity or situation in the 6 months before follow-up. 


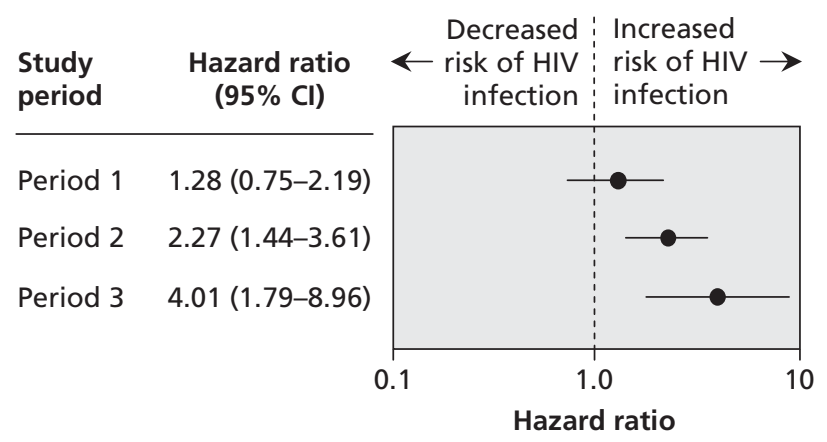

Figure 2: Association between daily smoking of crack cocaine and HIV seroconversion. A hazard ratio above 1.0 indicates an increased risk of HIV seroconversion. Period $1=$ May 1, 1996, to Nov. 30, 1999; period 2 = Dec. 1, 1999, to Nov. 30, 2002; period 3 = Dec. 1, 2002, to Dec. 31, 2005. Cl = confidence interval.

sured confounding factors related to HIV infection. With respect to unmeasured risk factors, crack cocaine is often smoked with the use of metal or glass pipes, which is known to produce wounds in and around the mouth. These wounds may make people who smoke crack more vulnerable to HIV transmission during activities such as oral sex or sharing of crack pipes. ${ }^{6,18} \mathrm{We}$ were unable to evaluate these possible risk factors, however, because the Vancouver Injection Drug Users Study did not investigate the occurrence of oral wounds or the sharing of crack pipes. With respect to possible unmeasured confounders, smokers of crack cocaine may have more HIV-positive individuals in their social networks. Therefore, any sexual or injection risk behaviour would represent an increased likelihood of HIV infection. ${ }^{19}$ Again, our study is limited by the inability to assess for this explanation. Finally, there may have been differential recall of HIV risk behaviour because of the psychological effects of crack cocaine. Individuals may have taken risks (e.g., unsafe sex) during binges of crack cocaine use that they did not recall when subsequently surveyed as part of the cohort study.

Although highly controversial, innovative public health programs that address the unique needs of people who smoke crack cocaine and that contribute to HIV prevention efforts may include the distribution of safer crack kits ${ }^{6}$ and the provision of supervised inhalation rooms.$^{20}$ In previous studies, drug users have reported a strong willingness to use the equipment provided in safer crack kits. ${ }^{5.21}$ Early evaluations have found this strategy to be associated with reductions in sharing smoking equipment. ${ }^{5,21}$ Although the provision of an inhalation room may be even more controversial, this strategy has been successfully implemented in several European settings. ${ }^{22}$ Feasibility studies in Vancouver showed a strong willingness among local smokers of crack cocaine to use such a facility. ${ }^{20,23}$ Inhalation rooms and the distribution of safer crack kits also afford the opportunity for health workers to engage with people who smoke crack. Such encounters may be critical for initiating efforts to address some of the needs for health care, social assistance and referral for addiction treatment of this often hidden population.

\section{Limitations}

Our study has several limitations. First, the Vancouver Injection Drug Users Study is not a random sample. However, the cohort is believed to be representative of injection drug users in the community. ${ }^{24}$ Second, this study relied on self-report, which may be vulnerable to socially desirable reporting. However, previous studies have shown social desirability to have limited confounding effect on the strength of association between HIV status and risk behaviours. ${ }^{25}$

\section{Conclusion}

Smoking of crack cocaine was found to be an independent risk factor for HIV seroconversion among people who were injection drug users. This finding points to the urgent need for evidence-based public health initiatives targeted at people who smoke crack cocaine. Innovative interventions that have the potential to reduce HIV transmission in this population, including the distribution of safer crack kits and medically supervised inhalation rooms, need to be evaluated.

\section{This article has been peer reviewed.}

Competing interests: Julio Montaner has received grants from, has served as an ad hoc advisor to, and has spoken at various events sponsored by Abbott, Argos Therapeutics, Bioject Inc., Boehringer Ingelheim, Bristol-Myers Squibb, Gilead Sciences, GlaxoSmithKline, Hoffmann-La Roche, JanssenOrtho, Merck Frosst, Pfizer, Schering, Serono Inc., TheraTechnologies, Tibotec and Trimeris. No competing interests declared by Kora DeBeck, Thomas Kerr, Kathy Li, Benedikt Fischer, Jane Buxton or Evan Wood.

Contributors: Kora DeBeck and Evan Wood were responsible for the study design and prepared the first draft of the analysis. Kathy Li contributed to the study design and conducted the statistical analyses. Thomas Kerr, Benedikt Fischer, Jane Buxton and Julio Montaner contributed to the main content and provided critical comments on the final draft. All of the authors approved the final version submitted for publication.

Acknowledgements: The authors thank the participants of the Vancouver Injection Drug Users Study for their willingness to be included in our study, as well as current and past investigators and staff of the Vancouver Injection Drug Users Study. They also thank Ruth Zhang, Calvin Lai and Viviane Lima for their statistical support and Deborah Graham, Tricia Collingham, Leslie Rae, Caitlin Johnston, Steve Kain and Brandon Marshall for their research and administrative assistance.

Funding: The study was supported by the US National Institutes of Health (grant nos. R01 DA011591 and R01 DA021525) and the Canadian Institutes of Health Research (CIHR; grant nos. HHP-67262, MOP-79297 and RAA79918). Kora DeBeck is supported by a Senior Graduate Trainee Award from the Michael Smith Foundation for Health Research and a CIHR Doctoral Research Award. Thomas Kerr is supported by the Michael Smith Foundation for Health Research and the CIHR. Benedikt Fischer is supported by a Senior Scholar Award from the Michael Smith Foundation for Health Research and holds the CIHR / Public Health Agency of Canada Chair in Applied Public Health. Julio Montaner has received an Avant-Garde award (DP1DA026182) from the National Institute of Drug Abuse, US National Institutes of Health.

\section{REFERENCES}

1. Public Health Agency of Canada. HIV and AIDS in Canada. Surveillance report to December 31, 2006. Ottawa (ON): Surveillance and Risk Assessment Division, Centre for Infectious Disease Prevention and Control, Public Health Agency of Canada; 2007.

2. Tyndall MW, Currie S, Spittal P, et al. Intensive injection cocaine use as the primary risk factor in the Vancouver HIV-1 epidemic. AIDS 2003;17:887-93.

3. Fischer B, Rehm J, Patra J, et al. Changes in illicit opioid use across Canada. CMAJ 2006; 175:1385.

4. Fairbairn N, Kerr T, Buxton JA, et al. Increasing use and associated harms of crystal methamphetamine injection in a Canadian setting. Drug Alcohol Depend 2007; 88:313-6. 
5. Leonard L, DeRubeis E, Pelude L, et al. "I inject less as I have easier access to pipes": injecting, and sharing of crack-smoking materials, decline as safer cracksmoking resources are distributed. Int J Drug Policy 2008;19:255-64.

6. Haydon E, Fischer B. Crack use as a public health problem in Canada: call for an evaluation of 'safer crack use kits.' Can J Public Health 2005;96:185-8.

7. Public Health Agency of Canada. I-Track: enhanced surveillance of risk behaviours among injecting drug users in Canada [pilot survey report]. Ottawa (ON): Surveillance and Risk Assessment Division, Centre for Infectious Disease Prevention and Control, Public Health Agency of Canada; 2004. Available: www.phac-aspc.gc.ca /i-track/index-psr-rep04-eng.php (accessed 2009 July 23).

8. Fischer B, Rehm J, Brissette S, et al. Illicit opioid use in Canada: comparing social, health, and drug use characteristics of untreated users in five cities (OPICAN study). J Urban Health 2005;82:250-66.

9. Edlin BR, Irwin KL, Faruque S, et al. Intersecting epidemics - crack cocaine use and HIV infection among inner-city young adults. N Engl J Med 1994;331:1422-7.

10. Wood E, Kerr T, Marshall BD, et al. Longitudinal community plasma HIV-1 RNA concentrations and incidence of HIV-1 among injecting drug users: prospective cohort study, BMJ 2009;338:b1649.

11. Fischer B, Rehm J, Patra J, et al. Crack across Canada: comparing crack users and crack non-users in a Canadian multi-city cohort of illicit opioid users. Addiction 2006;101:1760-70.

12. Wood E, Lloyd-Smith E, Li K, et al. Frequent needle exchange use and HIV incidence in Vancouver, Canada. Am J Med 2007;120:172-9.

13. Law CG, Brookmeyer R. Effects of mid-point imputation on the analysis of doubly censored data. Stat Med 1992;11:1569-78.

14. Spittal PM, Craib KJ, Wood E, et al. Risk factors for elevated HIV incidence rates among female injection drug users in Vancouver. CMAJ 2002;166:894-9.

15. Kuyper LM, Lampinen TM, Li K, et al. Factors associated with sex trade involvement among male participants in a prospective study of injection drug users. Sex Transm Infect 2004;80:531-5.

16. Schoenbaum EE, Hartel D, Selwyn PA, et al. Risk factors for human immunodeficiency virus infection in intravenous drug users. N Engl J Med 1989;321:874-9.

17. Therneau TM, Grambsch PM. Modeling survival data: extending the Cox model. New York (NY): Springer; 2000.

18. Porter J, Bonilla L, Drucker E. Methods of smoking crack as a potential risk factor for HIV infection: crack smokers' perceptions and behavior. Contemp Drug Probl 1997;24:319-47.

19. Latkin CA, Mandell W, Vlahov D. The relationship between risk networks' patterns of crack cocaine and alcohol consumption and HIV-related sexual behaviors among adult injection drug users: a prospective study. Drug Alcohol Depend 1996; 42:175-81.

20. Shannon K, Ishida T, Morgan R, et al. Potential community and public health impacts of medically supervised safer smoking facilities for crack cocaine users. Harm Reduct $J$ 2006;3:1.

21. Malchy L, Bungay V, Johnson J. Documenting practices and perceptions of 'safer' crack use: a Canadian pilot study. Int J Drug Policy 2008;19:339-41.

22. Hedrich D. European report on drug consumption rooms. Luxembourg City (Luxembourg): European Monitoring Centre for Drugs and Drug Addiction; 2004 Available: www.emcdda.europa.eu/attachements.cfm/att_2944_EN_consumption rooms report pdf (accessed 2009 July 23).

23. Collins CL, Kerr T, Kuyper LM, et al. Potential uptake and correlates of willing ness to use a supervised smoking facility for noninjection illicit drug use. J Urban Health 2005;82:276-84.

24. Tyndall MW, Craib KJ, Currie S, et al. Impact of HIV infection on mortality in a cohort of injection drug users. J Acquir Immune Defic Syndr 2001;28:351-7.

25. Latkin CA, Vlahov D, Anthony JC. Socially desirable responding and selfreported HIV infection risk behaviors among intravenous drug users. Addiction $1993 ; 88: 517-26$

Correspondence to: Dr. Evan Wood, BC Centre for Excellence in HIVIAIDS, 608-1081 Burrard St., Vancouver BC V6Z 1Y6;

fax 604 806-9044; uhri-ew@cfenet.ubc.ca

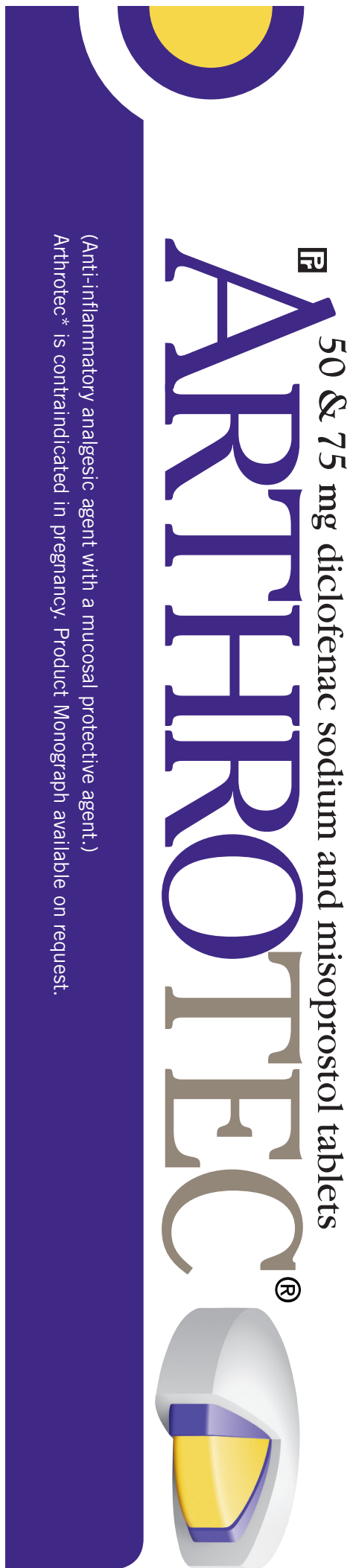

Working together for a heolthier world

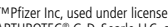
TMPfizer Inc, used under license
ARTHROTEC $C^{\oplus}$. D. Searle LLC,
Pfizer Canada Inc, licensee 